\title{
Comparison of predictive validity of Alvarado score and Lintula score in acute appendicitis in adults
}

\author{
Chandrabose K. ${ }^{1}$, Nair V. ${ }^{2}$ \\ ${ }^{1}$ Dr. Karpagavel Chandrabose, Assistant Professor, ${ }^{2}$ Dr.Velayudhan Nair, Assistant Professor; both authors are attached to \\ Department of General Surgery, Dr. SMCSI Medical College, Karakonam, Trivandrum, Kerala, India.
}

Address for Correspondence: Dr. Karpagavel Chandrabose, Assistant Professor, Department of General Surgery, Dr. SMCSI Medical College, Karakonam, Trivandrum, Kerala E-mail: drkarpagavel@gmail.com

\begin{abstract}
Background: Acute appendicitis is still one of the most common emergency encountered in surgical practice at all levels of health care. In resource poor settings, where diagnostic facilities for definitive diagnosis are not available objective clinical scoring systems play an important role in diagnosis and therapeutic decision making. Materials and Methods: To compare the predictive validity of Alvarado score and Lintula score in acute appendicitis in adults. The study was a prospective observational study conducted in the department of general surgery Dr. SMCSI Medical College, Karakonam. Trivandrum, between February to December 2016. A total of 130 subjects aged $\geq 1$ year with symptoms suggestive of acute appendicitis were included. Alvarado and Lintula scores were calculated for all subjects and were compared with histopathology findings. An Alvarado score of $\geq 7$, Lintula score of $\geq 21$ was considered as screening positive. Results: Alvarado score had a sensitivity of $63.15 \%(52.31 \%$ to $74.00 \%)$, specificity of $81.48 \%(71.12 \%$ to $91.84 \%)$. Positive predictive value \& Negative predictive value was $82.75 \%(72.03 \%$ to $92.47 \%)$ and $61.11 \%(49.85 \%$ to $72.37 \%)$ respectively. Diagnostic accuracy was $70.26 \%$ (62.95\% to $78.58 \%)$. Lintula score had a sensitivity of $72.36 \%(62.31 \%$ to $82.42 \%)$, specificity was $88.88 \%$ ( $80.50 \%$ to $97.27 \%)$. Positive predictive value \& Negative predictive value was $90.16 \%(82.69 \%$ to $97.63 \%)$ and $69.56 \%$ (58.70\% to $80.42 \%$ ) respectively. Diagnostic accuracy was $79 \%$ (95\%CI $72.25 \%$ to $86.20 \%$ ). Conclusions: Lintula score is more accurate than Alvarado score in the diagnosis of acute appendicitis.
\end{abstract}

Keywords: Acute appendicitis, Alvarado score, Lintula score

\section{Introduction}

Globally Acute appendicitis is the most common surgical emergency which causes acute abdominal pain and it may affect about $7 \%$ of people during their lifespan [1,2]. When compared with Western countries, the incidence of acute appendicitis is lower in Asian and African countries because of higher intake of dietary fiber [1]. Diagnosis of acute appendicitis remains as a challenging task, because of overlapping symptoms of appendicitis with a number of other conditions, especially at an early stage of presentation [3, 4]. Delay in diagnosis and management of appendicitis may increase the morbidity and mortality rates. Clinical diagnosis is accurate in $80 \%$ of cases and acts better than gold standard histopathology but still, there are records of negative appendectomy ranging from $15-30 \%$ and perforated appendectomy ranges are 10 to $30 \%$ [5-7]. Radiological imaging techniques are the good alternatives, with accurate diagnostic results but they have

Manuscript Received: $6^{\text {th }}$ June 2017

Reviewed: $16^{\text {th }}$ June 2017

Author Corrected: $24^{\text {th }}$ June 2017

Accepted for Publication: $30^{\text {th }}$ June 2017 some disadvantages like excessive cost, less availability, lack of radiologists etc. To fill this gap numerous diagnostic and clinical scores have been developed which are helpful to increase the accuracy of diagnosis in acute appendicitis [8-10].

Alvarado or MANTRELS scoring system was published in 1986, which was based on the mnemonic for remembering the combination of 8 signs and symptoms [8]. Lintula has developed a scoring system namely Lintula score for use in children but it was subsequently been validated in adults [11]. Different results of these scoring systems have been reported in the literature. Some studies showed that the scoring systems reduced the negative appendectomy rate by $50 \%$ [8], while some others reported that the diagnostic accuracy of the scores was low $[9,11]$.

Although in existing literature very few studies have compared the diagnostic accuracy of Alvarado and 
Lintula scores in the diagnosis of acute appendicitis, when seen in Indian scenario there are fewer studies are focused in this context [12-14]. The current study is aimed to assess the predictive validity of Alvarado score and Lintula score in acute appendicitis in adults.

\section{Aims and objectives}

To assess the predictive validity of Alvarado score and Lintula score in acute appendicitis in adults.

\section{Materials and Methods}

Study setting: The study was conducted in Dr. SMCSI Medical College, Karakonam, Trivandrum, in the department of general surgery.

Study design: The study was a Cross-sectional study.

Study period: The study was conducted between February 2016 to December 2016.

Sample size: This study has included 130 acute appendicitis patients.

\section{Inclusion criteria}

- Subjects with Acute appendicitis were included in the study.

- Aged above 1 year

\section{Exclusion criteria}

Patients with the following conditions were excluded from the study

- Infants

- Patients with acute abdominal pain because of some other pathologies.
- Patients with past history of surgery and those with acute abdominal trauma.

Ethical Considerations: The study was approved by the intuitional human ethics committee. Informed written consent was obtained from all study participants.

Confidentiality of the study participants was maintained throughout the study.

Study Procedure: Selected data were elicited from the patients and recorded in structured proforma. The data was collected on Socio-demographic parameters like age, gender. The history, clinical examination results, basic laboratory data (white blood cell; WBC) and were recorded on the previously prepared data sheets at the time of admission. Alvarado and Lintula scores described previously in the literature were calculated separately for each patient. An Alvarado score of 7 or greater [8], a Lintula score of 21 or greater [11] are indicative of appendicitis.

Statistical Analysis: Descriptive analysis of all the explanatory and outcome variables was done using frequency and proportion for categorical variables. The categorical variables were compared across the groups by chi-square test.

The utility of Alvarado or Lintula scores in predicting the diagnosis of acute appendicitis was assessed 95\% CI, sensitivity, specificity, false positive, false negative rates and predictive values for Alvarado and Lintula scores and presented appropriately. IBM SPSS statistical software, version 21 was used for data analysis.

\section{Results}

Table-1: Distribution of Age and Gender in study population $(\mathrm{N}=130)$.

\begin{tabular}{|c|c|c|}
\hline \multicolumn{2}{|c|}{ Frequency } & Percentage \\
\hline \multicolumn{2}{|c|}{ I. Age Groups } \\
\hline $1-9$ & 10 & $7.7 \%$ \\
\hline $10-19$ & 49 & $27.7 \%$ \\
\hline $20-29$ & 36 & $13.8 \%$ \\
\hline $30-39$ & 18 & $7.7 \%$ \\
\hline $40-49$ & 10 & $5.4 \%$ \\
\hline $50 \&$ Above & 7 & $57.6 \%$ \\
\hline & II. Gender & $42.3 \%$ \\
\hline Male & 75 & \\
\hline Female & 55 & \\
\hline
\end{tabular}


Among the study participants distribution of age has shown that majority of the participants were between 10 to 19 years $(37.7 \%)$ and only $7.7 \%$ were in between 1 to 9 years.

The proportion of subjects in 20 to 29 years, 30 to 39 years and 40 to 49 years were $27.7 \%, 13.8 \%$, and $7.7 \%$ respectively. Only $5.4 \%$ were at 50 and above. Females constituted only $42.3 \%$ of the study population compared to $57.6 \%$ males. (Table-1)

Table-2: Descriptive statistics of clinical parameter in study group $(\mathrm{N}=130)$.

\begin{tabular}{|c|c|}
\hline Clinical parameter & Percent in acute appendicitis \\
\hline Right iliac fossa pain & $100 \%$ \\
\hline Nausea/ vomiting & $61.8 \%$ \\
\hline Anorexia & $80 \%$ \\
\hline Rif tenderness & $100 \%$ \\
\hline Rebound tenderness & $46 \%$ \\
\hline Fever & $46 \%$ \\
\hline Leukocytosis & $61.8 \%$ \\
\hline
\end{tabular}

In the study group, all of the participants have the complaint of Right iliac fossa pain and if tenderness. Nausea/Vomiting was observed in $61.8 \%$ of people. The proportions of Anorexia rebound tenderness and fever were $80 \%, 46 \%$ and $46 \%$ respectively. Leukocytosis was seen in $61.8 \%$ of study population. (Table-2)

Table-3: Association between Alvarado Score and Acute appendicitis (N=130).

\begin{tabular}{|c|c|c|}
\hline \multirow{2}{*}{ Alvarado Score } & \multicolumn{2}{|c|}{ Acute Appendicitis } \\
\cline { 2 - 3 } & Positive & Negative \\
\hline 7 and above & $48(63.15 \%)$ & $10(18.51 \%)$ \\
\hline Below 7 & $28(36.84 \%)$ & $44(81.48 \%)$ \\
\hline
\end{tabular}

\begin{tabular}{|c|c|c|c|}
\hline \multirow{2}{*}{ Parameter } & \multirow{2}{*}{ Value } & \multicolumn{2}{|c|}{$\mathbf{9 5 \%}$ Confidence Interval } \\
\cline { 3 - 4 } & & Lower & Upper \\
\hline Sensitivity & $63.15 \%$ & $52.31 \%$ & $74.00 \%$ \\
\hline Specificity & $81.48 \%$ & $71.12 \%$ & $91.84 \%$ \\
\hline False positive rate & $18.51 \%$ & $8.16 \%$ & $28.87 \%$ \\
\hline False negative rate & $36.84 \%$ & $25.99 \%$ & $47.68 \%$ \\
\hline Positive predictive value & $82.75 \%$ & $73.03 \%$ & $92.47 \%$ \\
\hline Negative predictive value & $61.11 \%$ & $49.85 \%$ & $72.37 \%$ \\
\hline Diagnostic accuracy & $70.76 \%$ & $62.95 \%$ & $78.58 \%$ \\
\hline
\end{tabular}

Among adults who had 7 or more Alvarado score, $63.15 \%$ had acute appendicitis positive, whereas this proportion was only $36.84 \%$ among adults with Alvarado score $<7$. (Table-3)

Alvarado score had a sensitivity of $63.15 \%$ (95\% CI was 52.31\% to $74.00 \%)$ in predicting the diagnosis of Acute appendicitis. Specificity was $81.48 \%$ (95\% CI was $71.12 \%$ to $91.84 \%$ ), the False positive rate was $18.51 \%(95 \%$ CI was $8.16 \%$ to $28.87 \%$ ) and the False negative rate was $36.84 \%$ (95\% CI was $25.99 \%$ to $46.68 \%$ ).

Positive predictive value \& Negative predictive value was $82.75 \%$ (95\%CI $72.03 \%$ to $92.47 \%$ ) and $61.11 \%$ (95\% CI $49.85 \%$ to $72.37 \%$ ) respectively. Diagnostic accuracy was $70.26 \%$ (95\%CI $62.95 \%$ to $78.58 \%$ ). (Table 3 ) 
Table-4: Association between Lintula score and Acute appendicitis $(\mathrm{N}=130)$.

\begin{tabular}{|c|c|c|}
\hline \multirow{2}{*}{ Lintula score } & \multicolumn{2}{|c|}{ Acute Appendicitis } \\
\cline { 2 - 3 } & Positive & Negative \\
\hline 21 and above & $55(72.36 \%)$ & $6(11.11 \%)$ \\
\hline Below 21 & $21(27.63 \%)$ & $48(88.88 \%)$ \\
\hline
\end{tabular}

\begin{tabular}{|c|c|c|c|}
\hline \multirow{2}{*}{ Parameter } & \multirow{2}{*}{ Value } & \multicolumn{2}{|c|}{$\mathbf{9 5 \%}$ Confidence Interval } \\
\cline { 3 - 4 } & & Lower & Upper \\
\hline Sensitivity & $72.36 \%$ & $62.31 \%$ & $82.42 \%$ \\
\hline Specificity & $88.88 \%$ & $80.50 \%$ & $97.27 \%$ \\
\hline False positive rate & $11.11 \%$ & $2.728 \%$ & $19.49 \%$ \\
\hline False negative rate & $27.63 \%$ & $17.57 \%$ & $37.68 \%$ \\
\hline Positive predictive value & $90.16 \%$ & $82.69 \%$ & $97.63 \%$ \\
\hline Negative predictive value & $69.56 \%$ & $58.70 \%$ & $80.42 \%$ \\
\hline Diagnostic accuracy & $79 \%$ & $72.25 \%$ & $86.20 \%$ \\
\hline
\end{tabular}

Among adults who had 21 or more Lintula score, $72.36 \%$ had acute appendicitis positive, whereas this proportion was only $27.63 \%$ among adults with Lintula score $<21$. Lintula score had a sensitivity of $72.36 \%$ (95\% CI was $62.31 \%$ to $82.42 \%$ ) in predicting the diagnosis of Acute appendicitis. Specificity was $88.88 \%$ (95\% CI was $80.50 \%$ to $97.27 \%$ ), False positive rate was $11.11 \%$ (95\% CI was $2.72 \%$ to $19.49 \%$ ) and False negative rate was $27.63 \%$ (95\% CI was $17.57 \%$ to $37.68 \%$ ). Positive predictive value \& Negative predictive value was $90.16 \%$ (95\%CI $82.69 \%$ to $97.63 \%$ ) and $69.56 \%$ (95\% CI $58.70 \%$ to $80.42 \%$ ) respectively. Diagnostic accuracy was $79 \%$ (95\%CI $72.25 \%$ to $86.20 \%$ ). (Table-4)

\section{Discussion}

Although there was an advancement in diagnosis and treatment techniques, still appendicitis is a challenging surgical emergency with significant morbidity and mortality. The delay in the diagnosis and the treatment of the condition can lead to complications.

Radiologic imaging techniques have diagnostic accuracy, with few limitations like increasing the cost of additional radiation risk. To overcome all this limitations research is going on and a group of authors has developed scoring systems based on clinical findings and routine laboratory studies $[5-9,15]$. In this context, we aimed to assess the validity of Alvarado and Lintula scoring systems that are previously defined.

In the current study, people having 7 or more Alvarado score had $63.15 \%$ positive acute appendicitis cases where as in below 7 Alvarado score cases the proportion of positive appendicitis were $36.84 \%$ only.

Alvarado score had a sensitivity of $63.15 \%$, specificity was $81.48 \%$, the false positive rate was $18.51 \%$ and the false negative rate was $36.84 \%$. The positive predictive value \& negative predictive values were $82.75 \%$ and $61.11 \%$. Findings of the current study are similar to that reported by Limpawattanisiri et al[16], Memon ZA [17] and Shah et al [18].

International Journal of Surgery \& Orthopedics
In the study of Limpawattanisiri et al reported, that the sensitivity of the Alvarado score as $87.41 \%$, specificity of $74.39 \%$, PPV of $83.7 \%$ and concludes that Alvarado scoring system is reliable for diagnosis of acute appendicitis [16]. Diagnostic accuracy of Alvarado system in the current study is $70.76 \%$ and similarly, in the study of Memon ZA [17], Diagnostic accuracy was $89.8 \%$.

In our study 21 or more Lintula score participants had $73.36 \%$ positive acute appendicitis and $<21$ Lintula score persons had $27.63 \%$ positive acute appendicitis. Lintula scoring system had a sensitivity of $72.36 \%$, specificity was $88.88 \%$, the false positive rate was $11.11 \%$ and the false negative rate was $27.63 \%$. The positive predictive value \& negative predictive values were $90.16 \%$ and $69.56 \%$. The diagnostic accuracy was $79 \%$. Similarly, Lintula et al[15] have reported in this study $87 \%$ sensitivity of the score and $98 \%$ specificity. And supporting the predictive validity of Lintula score in acute appendicitis. Similar findings were found in the study of Yoldas et al [19].

Similar to our study, few other studies by Konan et al[14] have studied 41 patients above 65 years of age with acute appendicitis and equal number of age and gender matched controls admitted with other complaints. As per this study, 
both scores were observed to operate well in distinguishing between abdominal pain due to appendicitis and non-specific abdominal pain. The Alvarado score was a better predictor compared to the Lintula score. The authors have observed improved performance of the scores by minor modifications by excluding Two parameters (absent, tingling or highpitched bowel sounds and nausea). Study findings of Konan et al[14] were $77 \%$ sensitivity and $100 \%$ specificity for Alvarado score 7 or more. For Lintula score at 12 points cutoff had PPV, NPV was $87.2 \%, 87.8 \%$.

Senan et al [13] in their study have attempted to compare the predictive validity of Alvarado and Lintula scores in acute appendicitis along with two other scoring systems. As per area under the ROC curve, all the scores were reported to have very poor predictive value in diagnosing acute appendicitis. There was also the poor level of agreement between the scoring systems as shown by low Kappa statistic. The authors reported sensitivity and specificity of the four scoring systems were not sufficient enough in diagnosing acute appendicitis and recommended clinical judgment to a better alternative in absence of appropriate imaging facilities.

Wilasrusmee $\mathrm{C}$ et al. [12] in their recent systematic review have evaluated various scoring systems in predicting appendicitis. This review has included 44 studies published between 1974 to 2012, in which some of the studies have developed or modified existing diagnostic scoring systems and some studies have used existing validated models. Most frequently validated scores were Alvarado, modified Alvarado, Fenyo, and Eskelinen scoring systems.

The reviewers have reported only Eskelinen model to be derived based on multivariate regression methods and concluded that the research methods for scoring systems of appendicitis to be very inconsistent. Lintula Score was used by very few studies as per the review. The authors basing on this review have strongly recommended the need to develop more efficient scoring systems with better internal and external validity.

\section{Conclusions}

- Both Alvarado and Lintula scores have high sensitivity and specificity values in the diagnosis of acute appendicitis of adults.

- Diagnostic accuracy of Lintula score is slightly higher than Alvarado score and hence Lintula score is more accurate than Alvarado score in the diagnosis of acute appendicitis.

\section{Recommendation}

- Considering the inconsistency of reported validity and reliability of Alvarado and Lintula scoring systems, there is a strong need to conduct further large scale studies to strengthen the existing evidence on their utility

- Until strong evidence is available on the subjects, these scoring systems must be used with caution in making clinical decisions.

Conflict of interest: None declared.

Funding: Nil, Permission from IRB: Yes

\section{References}

1. Addiss DG, Shaffer N, Fowler BS, Tauxe RV. The epidemiology of appendicitis and appendectomy in the United States. Am J Epidemiol. 1990;132(5):910-25.

2. Franz MG, Norman J, Fabri PJ. Increased morbidity of appendicitis with advancing age. The American surgeon. 1995;61(1):40-4.

3. Bundy DG, Byerley JS, Liles EA, Perrin EM, Katznelson J, Rice HE. Does this child have appendicitis? Jama. 2007;298(4):438-51.

4. Singh K, Gupta S, Pargal P. Application of Alvarado Scoring System in Diagnosis of Acute Appendicitis. 2008.

5. Raza M, Habib L. Negative appendicectomy rate in current surgical practice. Journal of Postgraduate Medical Institute (Peshawar-Pakistan). 2011;23(3).

6. Das M, Gautam D, Roy H, Mukherjee A, Gaurav R, Sen S. Unnecessary appendicectomy in suspected cases of acute appendicitis. Journal of the Indian Medical Association. 2009;107(6):354, 6-7.

7. Townsend Jr CM, Beauchamp RD, Evers BM, Mattox KL. Sabiston textbook of surgery: Elsevier Health Sciences; 2016.

8. Alvarado A. A practical score for the early diagnosis of acute appendicitis. Annals of emergency medicine. 1986;15(5):557-64.

9. Ohmann C, Yang Q, Franke C. Diagnostic scores for acute appendicitis. Abdominal Pain Study Group. The European journal of surgery Acta chirurgica. 1995;161(4):273-81.

10. Lintula H, Kokki H, Pulkkinen J, Kettunen R, Gröhn $\mathrm{O}$, Eskelinen M. Diagnostic score in acute appendicitis. 


\section{Original Research Article}

Validation of a diagnostic score (Lintula score) for adults with suspected appendicitis. Langenbeck's Archives of Surgery. 2010;395(5):495-500.

11. Lintula H, Pesonen E, Kokki H, Vanamo K, Eskelinen M. A diagnostic score for children with suspected appendicitis. Langenbecks Arch Surg. 2005;390(2):16470,10.1007/s00423-005-0545-8.

12. Wilasrusmee C, Anothaisintawee T, Poprom N, McEvoy M, Attia J, Thakkinstian A. Diagnostic Scores for Appendicitis: A Systematic Review of Scores' Performance. British Journal of Medicine and Medical Research. 2014;4(2):711.

13. Sencan A, Aksoy N, Yıldız M, Okur Ö, Demircan Y, Karaca I. The evaluation of the validity of Alvarado, Eskelinen, Lintula and Ohmann scoring systems in diagnosing acute appendicitis in children. Pediatric surgery international. 2014;30(3):317-21.

14. Konan A, Hayran M, Kilic YA, Karakoç D, Kaynaroglu V. Scoring systems in the diagnosis of acute appendicitis in the elderly. Ulus Travma Acil Cerrahi Derg. 2011;17(5):396-400.
15. Lintula H, Kokki H, Pulkkinen J, Kettunen R, Grohn $\mathrm{O}$, Eskelinen M. Diagnostic score in acute appendicitis. Validation of a diagnostic score (Lintula score) for adults with suspected appendicitis. Langenbecks Arch Surg. 2010;395(5):495-500,10.1007/s00423-010-0627-0.

16. Limpawattanasiri C. Alvarado score for the acute appendicitis in a provincial hospital. J Med Assoc Thai. 2011;94(4):441-9.

17. Memon ZA, Irfan S, Fatima K, Iqbal MS, Sami W. Acute appendicitis: diagnostic accuracy of Alvarado scoring system. Asian Journal of Surgery. 2013;36 (4): 144-9.

18. Shah SWA, Khan CA, Malik SA, WaqasAjmel Munir Tarrar A, Buhatta IA. MODIFIED ALVARADO SCORE; ACCURACY IN DIAGNOSIS OF ACUTE APPENDICITIS IN ADULTS. Professional Medical Journal. 2010;17(4).

19. Yoldas O, Karaca T, Tez M. External validation of Lintula score in Turkish acute appendicitis patients. International Journal of Surgery. 2012;10(1):25-7.

\section{How to cite this article?}

Chandrabose K, Nair V. Comparison of predictive validity of Alvarado score and Lintula score in acute appendicitis in adults. Int J surg Orthopedics.2017;3(3):60-65.doi:10.17511/ijoso.2017.i03.02. 